\title{
РУССКОЯЗЫЧНАЯ ВЕРСИЯ ШКАЛЫ ОЦЕНКИ САМОЭФФЕКТИВНОСТИ ПСИХОЛОГОВ-КОНСУЛЬТАНТОВ И ПСИХОТЕРАПЕВТОВ
}

\author{
Н.В. КИСЕЛЬНИКОВА \\ М.М. ДАНИНА \\ Д.Э. КРАШЕНИННИКОВ ${ }^{\mathrm{a}}$ В.А. ПОДЖИО
}

"ФГБНУ «Психологический институт Российской академии образования», 125009, Россия, Москва, ул. Моховая, д. 9, стр. 4

\section{Russian adaptation of the Self-Efficacy Rating Scale for psychologists-consultants and psychotherapists}

\author{
N.V. Kiselnikova ${ }^{a}$, T.N. Almukhametova ${ }^{a}$, M.M. Danina ${ }^{a}$, E.A. Kuminskaya ${ }^{a}$, E.V. Lavrova ${ }^{a}$, \\ D.E. Krasheninnikov ${ }^{\mathrm{a}}$, V.A. Poggio ${ }^{\mathrm{a}}$
}

${ }^{a}$ FBSSI Psychological Institute of the Russian Academy of Education, 9, Bld 4, Mokhovaya Str., Moscow, 125009, Russian Federation

\section{Резюме}

В литературе представлены данные о связи самоэффективности психолога-консультанта (психотерапевта) с его профессиональной и образовательной успешностью. При использовании имеющихся шкал оценки самоэффективности возникают проблемы, связанные с самооценкой навыков по решению консультативных задач разного уровня сложности специалистами разного уровня подготовки. Отсутствует русскоязычный инструмент оценки самоэффективности психологаконсультанта (психотерапевта). Авторы разработали русскоязычный инструмент по измерению самоэффективности в трех областях деятельности психолога-консультанта (психотерапевта): навыки предпрактической подготовки, навыки по управлению сессией, навыки по управлению сложными клиническими ситуациями. Исследование включало следующие этапы: 1) перевод и адаптацию

\begin{abstract}
Studies show the connection between the self-efficacy of a counselor (or psychotherapist) and his success in professional and educational spheres. There are several selfefficacy assessment scales, but they have some problems associated with the situation, when entry-level professionals cannot assess their self-efficacy in high-level complexity tasks. There is no Russian-language tool to assess psychologist's self-efficacy. The aim of the article is to develop a Russian-language tool for measuring counselor's self-efficacy in three types of skills: problem-solving skills (explore/insight/ action), session management skills, and skills for managing complex clinical situations. This aim was achieved in the three steps: 1. Counselor Activity Self-Efficacy Scale (CASES) was translated and adapted; 2. The reliability-consistency and structure
\end{abstract}


опросника Counselor Activity Self-Efficacy Scales (CASES - Шкала самоэффективности консультанта); 2) проверку надежностисогласованности и структуры шкал в переведенном опроснике при помощи методов математической статистики; 3) проверку валидности при помощи опросника эмоционального интеллекта Д.В. Люсина, опросника эмпатии Дэвиса в адаптации Т.Д. Карягиной, Н.В. Кухтовой и шкалы позитивного и негативного аффекта (ШПАНА) в адаптации Е.Н. Осина. Выборку исследования составили 412 практикующих психотерапевтов и психологов-консультантов. Полученные результаты сопоставимы с данными по оригинальной версии опросника CASES и позволяют говорить о конструктной валидности русскоязычной Шкалы самоэффективности. Разработанный опросник может быть использован для оценки самоэффективности русскоязычных психологов-консультантов (психотерапевтов). Полученный опросник позволяет решать следующие практические и теоретические задачи: мониторинг естественного прогресса в консультировании обучающихся, изучение факторов, способствующих повышению самоэффективности психологов-консультантов (психотерапевтов), исследование степени варьирования оценок самоэффективности в зависимости от конкретных клиентских случаев.

Ключевые слова: самоэффективность, психологическое консультирование, психотерапия, помогающие навыки, эффективность психотерапии.

Кисельникова Наталья Владимировна заведующая лабораторией, лаборатория консультативной психологии и психотерапии; заместитель директора по научно-организационному развитию, ФГБНУ «Психологический институт Российской академии образования», кандидат психологических наук, доцент.

Сфера научных интересов: психотерапия, консультативная психология, терапия и профилактика депрессии, психология решения личностных проблем.

Контакты: nv_psy@mail.ru of the subscales in the translated questionnaire were checked using methods of mathematical statistics; 3 . Translated questionnaire was validated using the following questionnaires: Emotional Intelligence questionnaire by D.V. Lyusin, Interpersonal Reactivity Index (IRI) by Davis in adaptation by T.D. Karyagina, N.V. Kuhtova, and Positive and Negative Affect Schedule (PANAS) in the adaptation by E.N. Osin. Sample of the study consisted of 412 practicing counselors and psychotherapists. The results are comparable with the data on the original version of the CASES questionnaire and allow us to talk about the construct validity of the Russian-language Self-Efficacy Scale. The developed questionnaire can be used to assess the self-efficacy of the Russian-speaking counselors and psychotherapists. The obtained questionnaire can be used to solve the following practical and theoretical problems: monitoring the educational progress in psychotherapeutic trainings, studying the factors that increase the self-efficacy and studying the degree to which self-efficacy assessments vary depending on specific client cases.

Keywords: self-efficacy, psychological counseling, psychotherapy, helping skills, the effectiveness of psychotherapy.

Natalya V. Kiselnikova - Head of the Laboratory, Laboratory of Counseling Psychology and Psychotherapy, Psychological Institute of Russian Academy of Education, PhD in Psychology.

Research Area: psychotherapy, counseling psychology, therapy and prevention of depression, psychology of solving personal problems.

E-mail: nv_psy@mail.ru 
Альмухаметова Татьяна Николаевна научный сотрудник, лаборатория консультативной психологии и психотерапии, ФГБНУ «Психологический институт Российской академии образования».

Сфера научных интересов: эффективность психотерапии, профессиональные компетенции психотерапевта и психолога-консультанта, интегративные подходы в психотерапии. Контакты: kardoula@yandex.ru

Данина Мария Михайловна - старший научный сотрудник, лаборатория консультативной психологии и психотерапии, ФГБНУ «Психологический институт Российской академии образования, кандидат психологических наук».

Сфера научных интересов: психотерапия, консультативная психология, терапия и профилактика депрессивных состояний.

Контакты: mdanina@yandex.ru

Куминская Евгения Андреевна - научный сотрудник, лаборатория консультативной психологии и психотерапии, ФГБНУ «Психологический институт Российской академии образования».

Сфера научных интересов: психотерапия, консультативная психология, терапия и профилактика депрессивных состояний.

Контакты: j-aquarius@bk.ru

Лаврова Елена Васильевна - старший научный сотрудник, лаборатория консультативной психологии и психотерапии, ФГБНУ «Психологический институт Российской академии образования», кандидат психологических наук.

Сфера научных интересов: психотерапия, консультативная психология, терапия и профилактика депрессивных состояний.

Контакты: may_day@list.ru

Крашенинников Дмитрий Эдуардович лаборант, лаборатория психологии одаренности, ФГБНУ «Психологический институт Российской академии образования».

Сфера научных интересов: психотерапия, психологическое консультирование, гештальттерапия, эффективность психотерапии, профессиональные компетенции психотерапевта и психолога-консультанта.

Контакты: krasheninnikov.psy@mail.ru
Tatiana N. Almukhametova - Research Fellow, Laboratory of Counseling Psychology and Psychotherapy, Psychological Institute of Russian Academy of Education. Research Area: the effectiveness of psychotherapy, professional competence of a psychotherapist and a counselor psychologist, integrative approaches in psychotherapy.

E-mail: kardoula@yandex.ru

Mariya M. Danina - Senior Research Fellow, Laboratory of Counseling Psychology and Psychotherapy, Psychological Institute of Russian Academy of Education, PhD in Psychology. Research Area: psychotherapy, counseling psychology, therapy and prevention of depression.

E-mail: mdanina@yandex.ru

Evgeniya A. Kuminskaya - Research Fellow, Laboratory of Counseling Psychology and Psychotherapy, Psychological Institute of Russian Academy of Education. Research Area: psychotherapy, counseling psychology, therapy and prevention of depression.

E-mail: j-aquarius@bk.ru

Elena V. Lavrova - Research Fellow, Laboratory of Counseling Psychology and Psychotherapy, Psychological Institute of Russian Academy of Education, PhD in Psychology.

Research Area: psychotherapy, counseling psychology, therapy and prevention of depression.

E-mail: may_day@list.ru

Dmitriy E. Krasheninnikov - Laboratory Assistant, Laboratory of Psychology of giftedness, Psychological Institute of Russian Academy of Education.

Research Area: psychotherapy, psychological counseling, gestalt therapy, the effectiveness of psychotherapy, professional competence of a psychotherapist and counseling psychologist.

E-mail: krasheninnikov.pay@mail.ru 
Поджио Виктория Александровна - стажер, лаборатория консультативной психологии и психотерапии, ФГБНУ «Психологический институт Российской академии образования».

Сфера научных интересов: эффективность психотерапии и психологического консультирования, эмоциональное выгорание.

Контакты: victoria.poggio@gmail.com
Victoria A. Poggio - Laboratory intern, Laboratory of Counseling Psychology and Psychotherapy, Psychological Institute of Russian Academy of Education.

Research Area: counseling, the effectiveness of psychotherapy, burnout.

E-mail: victoria.poggio@gmail.com

Вопрос диагностики и возможностей повышения эффективности специалистов помогающих профессий остается высокоактуальным для исследователей с момента начала изучения психологического консультирования и психотерапии (Russell et al., 1984). Наиболее широко распространенный подход ранее заключался в применении общей социально-когнитивной теории А. Бандуры к изучению развития консультантов (Bandura, 1986, 1997). Согласно теории самоэффективности, ожидания относительно своего мастерства являются основными детерминантами поведенческих изменений. Было показано, что оценки самоэффективности положительно связаны с профессиональным и образовательным успехом (Sherer et al., 1982).

Развитие данного подхода нашло отражение в исследованиях в области консультативной психологии, направленных на изучение когнитивной структуры самоэффективности, т.е. убеждений консультантов о своих способностях реализовывать определенное поведение и использовать те или иные навыки, связанные с консультированием (Larson, Daniels, 1998). Самоэффективность консультантов исследовалась с помощью оценки тренерами, супервизорами и самими обучающимися консультантами собственных навыков - как общих, т.е. не связанных с конкретными направлениями работы с клиентами (Larson et al., 1992), так и специфических, связанных с реализацией узких профессиональных задач (O’Brien et al., 1997). Л.М. Ларсон, Дж.А. Дэниелс (Larson, Daniels, 1998) пришли к выводу, что существующие показатели самоэффективности психолога-консультанта положительно коррелируют с результатами работы, удовлетворенностью, а также с опытом работы - специалисты с бо́льшим стажем сообщают о более высокой эффективности, чем те, у кого меньше опыта. Отрицательные связи были обнаружены с беспокойством относительно своей деятельности. Кроме того, исследование показало, что вовлечение в практику, особенно в формате ролевых игр и моделирования, а также получение положительной обратной связи - как от клиентов, так и от супервизоров - способствует повышению самоэффективности у начинающих специалистов (Larson, Daniels, 1998; Reese et al., 2009). На примере студентов-консультантов также была продемонстрирована связь уровня их подготовки и самоэффективности в использовании базовых навыков консультирования (Sipps et al., 1988). Исследование Уотсона подтвердило, что опыт, связанный с консультированием, является важным предиктором самоэффективности (Watson, 1992), как и удовлетворенность жизнью (Pamukçu, 2011). 
В то же время отмечается недостаточность существующих на сегодняшний день исследований самоэффективности психологов-консультантов и психотерапевтов, определен ряд проблем в измерении самоэффективности и связанных с ней конструктов. Р.У. Лент, Дж. Хакетт и С.Д. Браун (Lent et al., 1998) говорят о нескольких проблемах в определении и измерении самоэффективности, отмечая, в частности, что существующие шкалы оценки самоэффективности консультанта часто: а) предполагают такой уровень понимания консультативных задач, который превышает знания начинающих и проходящих обучение специалистов; б) могут неправильно определять самоэффективность относительно более сложных навыков консультирования (например, способности консультировать клиента с клинической депрессией), поскольку не содержат отдельных пунктов, направленных на их оценку.

Целью данного исследования была разработка русскоязычного инструмента по измерению самоэффективности в нескольких областях деятельности психолога-консультанта, включающих воспринимаемую способность: 1) применять относительно структурированные помогающие навыки (Hill, O’Brien, 1999); 2) обрабатывать более интегративные, хотя и рутинные, задачи управления консультативной сессией (например, построение концептуальной модели проблемы клиента); 3) справляться с относительно продвинутыми или сложными клиническими ситуациями (например, эффективно работать с клиентом с клинической депрессией). Распределение шкал в разрабатываемом опроснике в соответствии с двумя основаниям - задачами консультирования и консультативными ситуациям - является обоснованным способом оценки деятельности консультанта, поскольку согласуется с точкой зрения на особенности развития и функционирования таких специалистов. Так, Р.К. Гудье, С.Р. Гуззардо (Goodyear, Guzzardo, 2000) полагают, что начинающие специалисты заняты овладением базовыми навыками помощи, которые со временем выступают основой чувства ролевой эффективности в ситуациях консультирования. Дальнейшее развитие связано в большей степени с освоением навыков, требующих повышения уровня сложности и творчества (например, управление кризисными ситуациями или работа с трудными типами клиентов).

\section{Метод}

С письменного согласия авторов Р.У. Лента и К.Е. Хилл были осуществлены перевод и адаптация опросника, являющегося признанным в мире инструментом оценки самоэффективности. Это опросник Counselor Activity Self-Efficacy Scales (CASES - Шкалы самоэффективности консультанта) (Lent et al., 2003), позволяющий помогающим практикам оценивать свои навыки консультирования. Он также используется при прохождении обучения психотерапии для самооценивания развивающихся навыков.

Опросник состоит из трех частей, соответствующих трем субдоменам. Каждая часть содержит вопросы о представлениях консультанта относительно его способности выполнять те или иные действия и решать различные профессиональные 
задачи. Первая часть посвящена общим компетенциям психолога-консультанта (психотерапевта), вторая часть - специальным компетенциям, а третья касается поведения в различных сложных ситуациях, с которыми специалист может столкнуться в работе. Респонденту предлагается оценить свою уверенность в той или иной компетенции по 10-балльной шкале (от 0 до 9).

Всего в опроснике выделяется 6 шкал. В первой части три подшкалы соответствуют трехступенчатой модели помогающих навыков К.М. О’Брайена (Hill, O’Brien, 1999). Шкала «Навыки выработки нового видения» содержит 6 пунктов, шкала «Навыки исследования» - 5 пунктов и шкала «Навыки действия» - 4 пункта. Вторая часть опросника содержит одну шкалу «Управление ходом сессии», состоящую из 10 пунктов, посвященных навыкам управления консультацией. В третьей части - две шкалы: «Конфликт отношений» (к ней относятся компетенции, помогающие справиться с конфликтом отношений, - 10 пунктов) и «Переживание дистресса клиентом» (компетенции, помогающие клиенту переживать дистресс, -6 пунктов). Таким образом, всего в оригинальном опроснике содержится 41 пункт.

Перевод опросника на русский язык осуществлялся в несколько этапов. На первом этапе 4 исследователя предлагали свои варианты перевода пунктов. Затем коллегиально согласовывался конечный вариант перевода. На втором этапе опросник рассылали фокус-группе психотерапевтов (3 человека). Экспертами выступили психологи, получившие базовое психологическое образование, а также прошедшие подготовку по одному из направлений психотерапии (системный семейный, интегративный и когнитивно-бихевиоральный подход). В группу экспертов были включены психологи, имеющие опыт работы более 7 лет. На последнем, третьем, этапе опросник подвергался обратному переводу с помощью русскоязычных экспертов, работающих на английском языке более 5 лет (2 человека). По итогам трех этапов в перевод были внесены корректировки с учетом реалий российской психотерапевтической практики. Например, пункт «challenges» в прямом переводе можно было бы назвать «вызовы», но такой термин широко не используется русскоязычными психологами, поэтому данный пункт был переформулирован следующим образом: «Работа с ограничениями, препятствиями, затруднениями». Раздел навыков, который в английском называется «Insight», на русский был переведен как «Навыки выработки нового видения», поскольку термин «инсайт» оказался во многом связан с философией гештальтподхода, что вызывало непонимание у психологов других направлений.

Дизайн шкал самоэффективности консультанта (CASES) опирается на следующие концепции: модель помогающих навыков (Hill, O’Brien, 1999) и связанные с ней исследования (Hill et al., 1999; Larson, 1998; Larson, Daniels, 1998; Lent et al., 1998), обобщение профессионального опыта тренеров и супервизоров психологов-консультантов. Оценка самоэффективности, по версии авторов, представляет собой самооценку трех доменов разных по содержанию навыков и способностей, куда входят, в частности, способности: а) применять базовые навыки помощи; б) управлять сессией; с) работать в сложных ситуациях консультирования. 
В оригинальной версии опросника первый субдомен («Самоэффективность помогающих навыков») включает «способность применять 18 навыков... которые относятся к уровню предпрактической подготовки» (Lent et al., 2003). В модели обучения (Hill, O’Brien, 1999) базовые навыки подразделяются на три группы: 1) исследовательские навыки, в которых основное внимание уделяется построению терапевтических отношений и получению необходимой информации от клиента; 2) навыки, направленные на понимание клиентских проблем; 3) навыки действия, которые направлены на содействие изменениям в эмоциях, мышлении или поведении клиента.

Второй субдомен ( «Управление сессией») включает воспринимаемую консультантами способность интегрировать основные навыки помощи в управлении специфическими задачами консультирования. Основное концептуальное различие между этим доменом и предыдущим - в оценке способности применять базовые помогающие навыки в условиях реальной сессии. Эта часть состоит из 17 пунктов.

Третий субдомен охватывает ряд ситуаций консультирования, которые могут оказаться сложными как для начинающих, так и для опытных консультантов. От участников требуется оценить, насколько они уверены в своей способности эффективной работы с разными типами клиентов, проблем или ситуаций. Под эффективностью работы подразумевается способность разработать успешный план, дать точные ответы на вопросы, использовать навыки саморегуляции, чтобы помочь клиенту решить свои проблемы. 24 пункта включают навык эффективно работать с клиентом, который пережил травмирующее жизненное событие, находится в клинической депрессии, не видит изменений в своем состоянии в процессе терапии и т.д. Этот субдомен рассматривается как относящийся к более продвинутым навыкам консультирования, тогда как первые два субдомена включают базовые навыки.

\section{Выборка}

В исследовании приняли участие 412 практикующих психотерапевтов и психологов-консультантов в возрасте от 18 до 67 лет (распределение по возрастным группам: 26 человек в возрасте от 18 до 25 лет, 117 человек $-25-35$ лет, 128 человек - 35-45 лет, 103 человека - 45-55 лет, 32 человека - 55-65 лет, 6 человек - 65 лет и старше), из них 350 женщин, 62 мужчины. Распределение по стажу работы следующее: меньше 1 года - 38 человек, от 1 до $3-74$ человека, от 4 до $7-89$ человек, от 7 до $10-68$ человек, 10 и больше 143 человека.

\section{Методики}

Для проверки валидности использовались следующие опросники:

1. Опросник эмоционального интеллекта Д.В. Люсина (Люсин, 2009). Шкалы: Управление чужими эмоциями (УЧЭ), Понимание своих эмоций (ПСЭ), УПравление своими эмоциями (УСЭ), Понимание чужих эмоций 
(ПЧЭ), Межличностный эмоциональный интеллект (МЭИ), Внутриличностный эмоциональный интеллект (ВЭИ), Управление эмоциями (УЭ), Понимание эмоций (ПЭ), контроль экспрессии (КЭ), Общий эмоциональный интеллект (Общий ЭИ).

2. Опросник эмпатии Дэвиса в адаптации Т.Д. Карягиной, Н.В. Кухтовой (Карягина, Кухтова, 2016). Шкалы: Децентрации (PT), Сопереживания (FS), Личного дистресса (PD), Эмпатической заботы (EC).

Шкала Perspective-Taking (дословно «Смена перспективы», в русском переводе - «Децентрация», РТ) направлена на измерение оценки индивидом своей склонности учитывать точку зрения других людей в повседневной жизни. Шкала оценивает тенденцию восприятия, понимания, принятия в расчет точки зрения, опыта другого человека.

Шкала Fantasy (в русском переводе - «Сопереживание», FS) отражает тенденцию к воображаемому отождествлению с чувствами и действиями вымышленных героев книг, фильмов, спектаклей и т.д.

Шкала Empathic Concern («Эмпатическая забота», ЕС) оценивает тенденцию человека испытывать чувства теплоты, сострадания и беспокойства по отношению к другим людям, выявляет «помогающее» отношение и симпатию к чьим-либо чувствам. В утверждениях шкалы описываются позитивные или негативные эмоциональные реакции на неудачу и проблемное состояние другого человека.

Шкала Personal Distress («Личный дистресс», PD) позволяет выявить чувства неловкости и дискомфорта при реакции на эмоции других людей в ситуациях оказания помощи, в напряженном межличностном взаимодействии и при наблюдении переживаний других людей, а также чувства неловкости и дискомфорта, направленные, в отличие от эмпатической заботы, на себя.

3. Шкала позитивного и негативного аффекта (ШПАНА) в адаптации Е.Н. Осина (2012). Шкалы: Позитивный аффект (ПА), Негативный аффект (HA). Разработана на основе англоязычной методики PANAS (Positive and Negative Affect Schedule). Методика PANAS операционализирует два основных измерения эмоций, которые воспроизводятся в различных исследованиях, посвященных факторному анализу самооценки настроения, а также многомерному шкалированию выражений лица и прилагательных, обозначающих эмоции.

Все участники заполнили указанный выше пакет опросников вместе с краткой анкетой с демографическими данными и информацией об опыте консультирования.

\section{Результаты}

На первом этапе была осуществлена проверка надежности-согласованности и структуры шкал. Проверка надежности-согласованности пунктов опросника была проведена путем расчета коэффициента альфа Кронбаха для каждого пункта. За критическое значение был принят коэффициент 0.7 (Митина, 2015). Шкалы, показавшие большее значение, вошли в итоговую версию 
опросника (см. приложение 1). В результате проверки надежности-согласованности опросника все пункты были оставлены (см. таблицу 1).

Для моделирования структуры опросника использовался метод конфирматорного факторного анализа, который применялся ко всем пунктам. Моделирование структурными уравнениями было проведено при помощи Amos Graphics, версия 19.0, метод максимального правдоподобия. В ходе анализа проверялось соответствие структуры русскоязычного опросника структуре оригинального. В результате была подтверждена исходная шестифакторная модель (рисунок 1).

Таблица 1

Проверка надежности русскоязычной версии Шкалы оценки самоэффективности психологов и психотерапевтов

\begin{tabular}{|c|c|}
\hline Шкала & $\boldsymbol{\alpha}$ Кронбаха \\
\hline Навыки выработки нового видения & 0.71 \\
\hline Навыки исследования & 0.82 \\
\hline Навыки действия & 0.81 \\
\hline Управление ходом сессии & 0.92 \\
\hline Конфликт отношений & 0.90 \\
\hline Переживание дистресса клиентом & 0.85 \\
\hline
\end{tabular}

Рисунок 1

Шестифакторная модель опросника

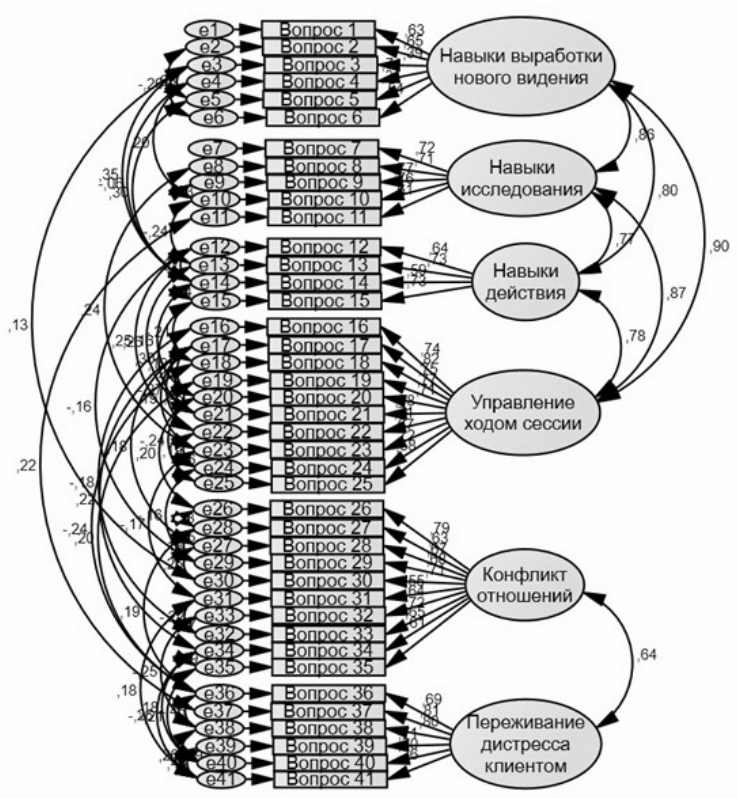

хи квадрат=1175,146; df=720; CFI=,924; RMSEA $=, 049 ; \mathrm{P}=, 000 ;$ pcLose $=, 595$ 
Показатель CFI не ниже 0.90 указывает на хорошее соответствие модели данным. Также в пользу полученной модели свидетельствуют показатели RMSEA, который должен быть меньше 0.05 (в нашей модели он равен 0.049), и PCLOSE, превышающий 0.5 (в нашей модели он равен 0.595). Соотношение $\chi^{2}$ к степеням свободы (DF) должно быть меньше двух, что также соблюдено в данной модели.

На следующем этапе проводилось исследование конструктной валидности методики. В частности, исследовались связи показателей Опросника самоэффективности с показателями Шкалы позитивного и негативного аффекта, Опросника эмпатии и Опросника эмоционального интеллекта. На основе известных эмпирических фактов были сформулированы следующие корреляционные гипотезы: показатели по субшкалам Опросника самоэффективности будут положительно коррелировать с показателями шкал эмпатической заботы и сопереживания (по опроснику М. Дэвиса) и отрицательно коррелировать с показателями эмпатического дистресса (по опроснику М. Дэвиса), положительно коррелировать с показателями субшкал эмоционального интеллекта (по опроснику Д.В. Люсина).

Корреляционные гипотезы проверялись посредством расчета коэффициента корреляции Пирсона. Результаты опросников были представлены в баллах. В таблице 2 показаны значимые связи, полученные в результате корреляционного анализа по критерию Пирсона $(p<0.001)$.

Таблица 2

Результаты корреляционного анализа

\begin{tabular}{|l|c|c|c|c|c|c|}
\hline & Cases 1.1 & Cases 1.2 & Cases 1.3 & Cases 2 & Cases 3.1 & Cases 3.2 \\
\hline УЧЭ & 0.226 & 0.357 & 0.320 & 0.366 & 0.355 & 0.229 \\
\hline ПСЭ & 0.233 & 0.364 & 0.278 & 0.391 & 0.365 & \\
\hline УСЭ & 0.221 & 0.382 & 0.319 & 0.395 & 0.369 & \\
\hline ПЧЭ & & 0.280 & & 0.308 & & 0.203 \\
\hline МЭИ & & 0.355 & 0.260 & 0.376 & 0.294 & 0.241 \\
\hline ВЭИ & 0.228 & 0.398 & 0.277 & 0.417 & 0.367 & 0.209 \\
\hline ПЭ & 0.223 & & 0.246 & 0.398 & 0.313 & 0.209 \\
\hline УЭ & 0.233 & 0.382 & 0.331 & 0.393 & 0.375 & 0.225 \\
\hline КЭ & & 0.219 & & 0.217 & & \\
\hline Общий ЭИ & 0.231 & 0.396 & 0.281 & 0.416 & 0.349 & 0.234 \\
\hline РТ & & 0.202 & & & & \\
\hline FS & 0.197 & 0.311 & 0.245 & 0.339 & 0.382 & 0.222 \\
\hline РD & -0.201 & & -0.320 & -0.286 & -0.396 & \\
\hline ЕС & & 0.266 & & 0.227 & 0.180 & \\
\hline ПА & & 0.338 & 0.215 & 0.332 & 0.279 & 0.181 \\
\hline НА & & & & & -0.260 & \\
\hline
\end{tabular}

Примечание. Cases 1.1 - шкала «Навыки выработки нового видения», Cases 1.2 - шкала «Навыки исследования», Cases 1.3 - шкала «Навыки действия», Cases 2 - шкала «Управление ходом сессии», Cases 3.1 - шкала «Конфликт отношений», Cases 3.2 - шкала «Переживание дистресса клиентом». 


\section{Обсуждение}

Мы получили результаты, сопоставимые с данными оригинальной версии опросника CASES. Шкалы «Исследование», «Новое видение», «Действия» и «Управление сессией» оценивают самоэффективность консультанта, или воспринимаемую способность выполнять конкретные задачи консультирования в относительно несложных условиях. Масштабы клиентского дистресса (шкала «Переживание дистресса клиентом») и конфликта отношений (шкала «Конфликт отношений»), напротив, отражают воспринимаемое умение справляться с более сложными ситуациями консультирования (Bandura, 1997; Lent et al., 2000; Lent et al., 1998). Оба типа самоэффективности являются необходимыми для профессионального развития психолога-консультанта.

Важной особенностью данного исследования является то, что оно ориентировано на свободное от контекста использование определенных навыков, т.е. не связано с конкретной информацией о клиенте, репрезентацией его или ее проблемы, с поведением на сессии и т.д. Такая внеконтекстная оценка может быть полезна в работе с консультантами, находящимися на начальной стадии профессионального развития и имеющими мало опыта работы с разными типами клиентов.

Адаптированные шкалы CASES продемонстрировали сильные корреляции с отрицательным и положительным аффектом и умеренные - в оригинальной версии. Предполагается, что с ростом опыта и самоэффективности профессионалы должны испытывать меньше стресса, чувствовать себя более комфортно в ситуациях консультирования и, соответственно, отчитываться о меньшем негативном аффекте.

Подтвержденные гипотезы о связи показателей опросника с баллами по Опроснику эмпатии и Опроснику эмоционального интеллекта позволяют говорить о конструктной валидности русскоязычной Шкалы самоэффективности. Так, показатели по субшкалам Опросника самоэффективности положительно коррелируют с показателями шкал эмпатической заботы и сопереживания и отрицательно - с показателями эмпатического дистресса (по опроснику М. Дэвиса), а также положительно коррелируют с показателями субшкал эмоционального интеллекта (по опроснику Д.В. Люсина).

Полученные результаты согласуются с исследовательскими предположениями, здравым смыслом и практической интуицией.

Схожие данные были получены турецкими (Pamukçu, Demir, 2013) и малазийскими (Bagheri et al., 2011) исследователями при валидизации и проверке надежности версий Опросника самоэффективности на соответствующих языках. Так, для турецкой версии, апробированной на 470 интернах-консультантах, были получены высокие коэффициенты внутренней согласованности, подтверждена исходная факторная модель на уровне трех частей опросника и их подшкал, а проверка конвергентной валидности показала значимые положительные корреляции CASES со шкалой навыков консультанта и другими подобными субшкалами. Предварительная проверка надежности опросника 
на малазийском языке, проведенная на 30 учащихся последнего года обучения по программе консультирования, подтвердила общую внутреннюю надежность шкалы (альфа Кронбаха 0,98) и отдельных субшкал опросника. Это дает определенные основания полагать, что шкалы измеряют некоторые инварианты деятельности психолога-консультанта, не зависящие от культурных факторов.

Итак, Опросник самоэффективности может рассматриваться как удобный и валидный инструмент для самооценки психологами-консультантами своих компетенций - как в процессе обучения, так и в ходе профессиональной деятельности. Помимо этого, на основе данного опросника могут быть разработаны шкалы или карты наблюдений для оценки навыков психолога-консультанта другими специалистами (супервизорами, тренерами, преподавателями) в реальной работе с клиентами. Сопоставление самооценок и оценок могло бы дать более объемную картину проявления тех или иных компетенций. Следует отметить, что подобные методики широко применяются в образовательной, супервизионной и намеренной (deliberate) практике за рубежом, однако отсутствуют на русском языке. В силу этого полученный опросник обладает ценностью не только как исследовательский, но и практический инструмент.

\section{Ограничения исследования}

Существует ряд ограничений относительно возможности обобщать или распространять полученные выводы на широкий класс случаев. Во-первых, в данном исследовании отсутствует проверка тест-ретестовой надежности опросника. Во-вторых, в выборке преобладают консультанты с большим стажем работы. В-третьих, гендерный состав выборки не сбалансирован (хотя и отражает реальные пропорции специалистов разных гендеров в консультировании). В-четвертых, хотя самоэффективность отчасти определяет, насколько хорошо люди организуют и используют свои навыки (Bandura, 1986), она не рассматривается в качестве замены фактического или объективно оцениваемого навыка. Люди иногда неправильно воспринимают или искажают оценку своих возможностей, особенно в определенных условиях, например, когда им не хватает знаний об условиях задачи (Bandura, 1997).

Одним из ключевых ограничений опросника выступает его концептуальная «привязанность» к модели навыков помогающих практиков К. Хилл и Р. Лента, которая может рассматриваться только как частично подходящая модель для описания значимых составляющих работы психологов-консультантов разных направлений и школ. Несмотря на указанные ограничения, опросник обладает рядом преимуществ. Так, базовые помогающие навыки содержат поведенческие описания каждого компонента, которые могут применяться даже неопытными консультантами. Наконец, формулирование пунктов опросника согласуется с аналогичными формулировками в других концепциях самоэффективности (Chow et al., 2015; Larson, Daniels, 1998) и отражает содержание поведенческих и когнитивных навыков, что обеспечивает конструктную валидность инструмента. 


\section{Заключение}

Данное исследование предполагает несколько направлений для будущих исследований, профессиональной подготовки и практики, ориентированной на повышение эффективности работы психологов-консультантов. В частности, данный опросник можно использовать для мониторинга естественного прогресса в консультировании у обучающихся. Также самостоятельным направлением выступает изучение факторов, которые способствуют повышению самоэффективности консультантов. Результаты Р. Лента, К. Хилл показывают, что оценки CASES растут с получением дополнительного опыта консультирования. Другой вопрос, заслуживающий внимания, - это степень, в которой оценки самоэффективности специфичны для конкретных клиентских случаев. Р. Лент и соавт. предположили, что самоэффективность может варьироваться в зависимости от конкретных клиентов, с которыми имеет дело консультант (Lent et al., 1998). В таком случае оценки самоэффективности по отношению к конкретным клиентам, вероятно, будут более изменчивыми, чем глобальные оценки не зависящей от контекста самоэффективности. Также может быть, что по сравнению с общими оценками самоэффективности специфичные для клиентских случаев оценки являются лучшими предикторами поведения в профессиональной деятельности. Исследования этих проблем могут расширить текущее понимание эффективности консультирования и того, как оно протекает на практике на уровне сессий.

Также полезно соотнести данные оценки самоэффективности с объективными показателями навыков (например, оценками наблюдателей) и с оценками работы консультанта на реальных консультациях. Важно изучить влияние самоэффективности консультанта на реальный процесс и результат изменений у клиента, а также проанализировать механизмы этого влияния. Например, существуют ли определенные поведенческие «сигналы» у консультанта с высокой самоэффективностью, которые повышают уровень доверия клиента и его приверженности лечению?

Подобные исследования могут, в частности, пролить свет на полезность дополнительных аспектов поведения консультанта и расширить понимание того, как консультанты воспринимают конкретные проблемы клиентов, например, напряженные отношения и другие трудности, возникающие на сессии, а затем реагируют на них.

\section{Литература}

Карягина, Т. Д., Кухтова, Н. В. (2016). Тест эмпатии М. Дэвиса: содержательная валидность и адаптация в межкультурном контексте. Консультативная психология и психотерапия, 24(4), $33-61$.

Люсин, Д. В. (2009). Опросник на эмоциональный интеллект ЭмИн: новые психометрические данные. В кн. Д. В. Люсин, Д. В. Ушаков (ред.), Социальный и эмоциональный интеллект: от моделей к измерениям (с. 264-278). М.: Институт психологии РАН. 
Митина, О. В. (2015). Альфа Кронбаха: когда и зачем ее считать. В Н.А. Батурин и др. (ред.), Современная психодиагностика России. Преодоление кризиса: сборник материалов III Всероссийской конференщии по психологиеской диагностики (Т. 1, с. 95-104). Челябинск: Издательский центр ЮУрГУ.

Осин, Е. Н. (2012). Измерение позитивных и негативных эмоций: разработка русскоязычного аналога методики PANAS. Психология. Журнал Высшей школы экономики, 9(4), 91-110.

Ссылки на зарубежные источники см. в разделе References.

\section{References}

Bagheri, E., Jaafar, W. M. W., \& Baba, M. (2011). Reliability analysis of the Counselor Activity SelfEfficacy Scale (CASES) in a Malaysian context: A preliminary study. Procedia - Social and Behavioral Sciences, 30, 871-875.

Bandura, A. (1986). Social foundations of thought and action: A social cognitive theory. Prentice-Hall. Bandura, A. (1997). Self-efficacy: The exercise of control. Freeman.

Chow, D. L., Miller, S. D. Seidel, J. A., Kane, R. T., Thornton J. A., \& Andrews, W. P. (2015). The role of deliberate practice in the development of highly effective psychotherapists. Psychotherapy, 52(3), 337-345.

Goodyear, R. K., \& Guzzardo, C. R. (2000). Psychotherapy supervision and training. In S. D. Brown \& R. W. Lent (Eds.), Handbook of counseling psychology (pp. 83-108). John Wiley \& Sons Inc.

Hill, C. E., \& O'Brien, K. M. (1999). Helping skills: Facilitating exploration, insight, and action. American Psychological Association.

Hill, C. E., O’Brien, K. M., Kolchakian, M. R., Quimby, J. L., Kellems, I. S., Zack, J. S., \& Herbenick, D. L. (1999). Training undergraduate students to become helpers: An investigation of changes in performing helping skills, self-efficacy about helping, and anxiety about helping (Unpublished manuscript). University of Maryland, College Park.

Karyagina, T. D., \& Kukhtova, N. V. (2016). Test empatii M. Devisa: soderzhatel'naya validnost' i adaptatsiya v mezhkul'turnom kontekste [The Empathy Test by M. Davis: content validity and adaptation in the intercultural context]. Konsul'tationaya Psikhologiya i Psikhoterapiya, 24(4), 33-61.

Larson, L. M. (1998). The social cognitive model of counselor training. The Counseling Psychologist, 26, $219-273$.

Larson, L. M., \& Daniels, J. A. (1998). Review of the counseling self efficacy literature. The Counseling Psychologist, 26, 179-218.

Larson, L. M., Suzuki, L. A., Gillespie, K. N., Potenza, M. T., Bechtel, M. A., \& Toulouse, A. (1992). Development and validation of the Counseling Self-Estimate Inventory. Journal of Counseling Psychology, 39, 105-120.

Lent, R. W., Brown, S. D., \& Hackett, G. (2000). Contextual supports and barriers to career choice: A social cognitive analysis. Journal of Counseling Psychology, 47, 36-49.

Lent, R. W., Hackett, G., \& Brown, S. D. (1998). Extending social cognitive theory to counselor training: Problems and prospects. The Counseling Psychologist, 26, 295-306.

Lent, R. W., Hill, C. E., \& Hoffman, M. A. (2003). Development and validation of the Counselor Activity Self-Efficacy Scales. Journal of Counseling Psychology, 50(1), 97-108.

Lyusin, D. V. (2009). Oprosnik na emotsional'nyi intellekt EmIn: novye psikhometricheskie dannye [Emotional Intelligence questionnaire EmIn: new psychometric data]. In D. V. Lyusin \& D. V. 
Ushakov (Eds.), Sotsial'nyi i emotsional'nyi intellekt: ot modelei k izmereniyam [Social and emotional intelligence: from models to measures] (pp. 264-278). Moscow: Institute of Psychology of the RAS. Mitina, O. V. (2015). Al'fa Kronbaha: kogda i zachem ee schitat' [Cronbach's alpha: when and why to calculate it]. In N.A. Baturin et al. (Eds.), Sovremennaya psihodiagnostika Rossii. Preodolenie krizisa: sbornik materialov III Vserossijskoj konferencii po psihologicheskoj diagnostiki [Modern psychodiagnostics of Russia. Overcoming the crisis: collection of materials of the $3 \mathrm{~d}$ all-Russian conference on psychological diagnostics] (Vol.1, pp. 95-104). Chelyabinsk: Izdatel'skij centr YUUrGU.

O’Brien, K. M., Heppner, M. J., Flores, L. Y., \& Bikos, L. H. (1997). The Career Counseling SelfEfficacy Scale: Instrument development and training applications. Journal of Counseling Psychology, 44, 20-31.

Osin, E. N. (2012). Measuring positive and negative affect: Development of a Russian-language analogue of PANAS. Psychology. Journal of Higher School of Economics, 9(4), 91-110. (in Russian)

Pamukçu, B. (2011). The investigation of counseling self-efficacy levels of counselor trainees (Unpublished master's thesis). Department of Educational Sciences, Middle East Technical University, Ankara. (in Turkish)

Pamukçu, B., \& Demir, A. (2013). The validity and reliability study of the Turkish version of counseling self-efficacy scale. Journal of Turkish Psychological Counseling and Guidance, 5(40), 212-221.

Reese, R. J., Usher, E. L., Bowman, D. C., Norsworthy, L. A., Halstead, J. L., Rowlands, S. R., \& Chisholm, R. R. (2009). Using client feedback in psychotherapy training: An analysis of its influence on supervision and counselor self-efficacy. Training and Education in Professional Psychology, 3(3), 157-168. https://doi.org/10.1037/a0015673

Russell, R. K., Crimmings, A. M., \& Lent, R. W. (1984). Counselor training and supervision: Theory and research. In S. D. Brown \& R. W. Lent (Eds.), Handbook of counseling psychology (pp. 625-681). Wiley.

Sherer, M., Maddux, J. E., Mercandante, B., Prentice-Dunn, S., Jacobs, B., \& Rogers, R. W. (1982). The Self-Efficacy Scale: Construction and validation. Psychological Reports, 51(2), 663-671. https://doi.org/10.2466/pr0.1982.51.2.663

Sipps, G. J., Sugden, G. J., \& Faiver, C. M. (1988). Counselor training level and verbal response type: Their relationship to efficacy and outcome expectations. Journal of Counseling Psychology, 35(4), 397-401.

Watson, D. P. (1992). Counseling self-efficacy and counseling competence: A comparative study of clergy and counselors-in-training. (Unpublished doctoral dissertation). Purdue University, West Lafayette, IN. Retrieved from Dissertations \& Theses: Full Text. (Publication No. AAT 9314098) 


\section{Шкала оценки самоэффективности психологов-консультантов и психотерапевтов}

Приложение 1

\section{Инструкция}

Перед вами вопросы, касающиеся ваших представлений о профессиональных компетенциях - ваших способностях выполнять те или иные действия в качестве консультирующего психолога и решать различные профессиональные задачи. Опросник состоит из трех частей. Первая часть посвящена общим компетенциям психолога-консультанта (психотерапевта), вторая часть - специальным компетенциям, а третья касается поведения в различных сложных ситуациях, с которыми вы можете столкнуться в работе. Пожалуйста, старайтесь отвечать максимально честно и в соответствии с представлениями о своих компетенциях в данный момент. Здесь нет правильных и неправильных ответов. Отметьте на шкале ту цифру, которая в большей степени отражает вашу уверенность в наличии у вас той или иной компетенции на данный момент.

\section{Чacms 1}

Часть 1.1. Навыки выработки нового видения

Пожалуйста, отметьте на шкале, насколько вы уверены в своей способности эффективно применять такие общие навыки в работе с большинством ваших клиентов в течение следующей недели:

1) непосредственность (умение раскрывать свои чувства, возникающие в связи с работой с клиентом: по отношению к клиенту, терапевтическим отношениям или к себе самому);

2) интерпретация (умение высказывать идеи, которые выходят за рамки того, что клиент говорит открыто, и позволяют ему по-новому увидеть свои поведение, мысли или чувства);

3) умение рассказывать о собственных инсайтах (умение описывать свой личный опыт, после которого вам удалось увидеть нечто по-новому);

4) работа с ограничениями, препятствиями, затруднениями (умение указать на несоответствия, противоречия или иррациональные убеждения, которые клиент не замечает, не может или не хочет изменить);

5) самораскрытие (умение раскрывать перед клиентом факты из истории собственной жизни, делиться чувствами);

6) преднамеренное молчание (умение брать паузу, чтобы дать клиенту время соприкоснуться с мыслями или чувствами).

\section{Часть 1.2. Навыки исследования}

Пожалуйста, отметьте на шкале, насколько вы уверены в своей способности эффективно применять такие общие навыки в работе с большинством ваших клиентов в течение следующей недели:

1) открытые вопросы (умение задавать вопросы, которые помогают клиенту прояснить или исследовать мысли и чувства);

2) слушание (умение услышать и понять смысл сообщения, высказанного клиентом);

3 ) отражение чувств (умение повторить или перефразировать утверждения клиента, акцентируя внимание на его или ее чувствах); 
4) перефразирование (умение повторить или перефразировать кратко, конкретно и ясно то, что сказал клиент);

5) невербальное соприсутствие (умение проявлять невербальное внимание к клиенту).

\section{Часть 1.3. Навыки действия}

Пожалуйста, отметьте на шкале, насколько вы уверены в своей способности эффективно применять такие общие навыки в работе с большинством ваших клиентов в течение следующей недели:

1) информирование (умение знакомить клиента с данными, точками зрения, фактами, источниками информации);

2 ) ролевая игра и тренировка поведения (умение помочь клиенту в отработке определенного поведения или роли во время сессии);

3) прямое руководство (умение дать клиенту рекомендации, предписания, которые подразумевают конкретные действия);

4) домашнее задание (умение разработать и дать терапевтические задания для их выполнения клиентами между сессиями).

\section{Часть 2. Управление ходом сессии}

Пожалуйста, отметьте на шкале, насколько вы уверены в своей способности эффективно выполнять перечисленные ниже задачи при взаимодействии с большинством ваших клиентов в течение следующей недели:

1) помогать клиенту понимать его/ее мысли, чувства и действия;

2) знать, как отреагировать (что сделать или сказать) на высказывание клиента;

3) помогать клиенту говорить о его проблемах на более глубоком уровне;

4) выстраивать четкое представление о вашем клиенте и его трудностях;

5) помогать клиенту исследовать его/ее мысли, чувства и действия;

6) использовать наиболее подходящий помогающий навык соответственно актуальным потребностям клиента;

7) помогать клиенту ставить реалистичные цели в консультировании;

8) следить за ходом сессии и быть сосредоточенным;

9) осознавать цели своих действий в ходе консультирования;

10) помогать клиенту решить, какие действия предпринять относительно его/ее проблем.

\section{Чaсmь 3}

\section{Часть 3.1. Конфликт отношений}

Пожалуйста, отметьте на шкале, насколько вы уверены в своей способности эффективно работать в описанных ниже ситуациях в течение следующей недели. Действовать эффективно - означает разрабатывать план лечения, придумывать подходящие ответы на консультациях, сохранять самообладание и поддерживать контакт с клиентом во время сложных взаимодействий и, в конечном итоге, помогать клиенту решать его или ее проблемы.

Насколько вы уверены, что сможете эффективно работать в течение следующей недели с клиентом, если... 
1) ...у вас возникают по отношению к клиенту негативные реакции (например, скука, раздражение)?

2) ...терапия с клиентом зашла в тупик?

3) ...клиент хочет от вас больше, чем вы готовы дать (в том числе советов о том, как ему поступить, контактов между встречами)?

4) ...клиент имеет дело с проблемами, с которыми вам лично тяжело справляться?

5) ...клиент ведет себя манипулятивно во время сессии?

6) ...клиент обладает низким уровнем рефлексии?

7) ...клиент сексуально привлекает вас?

8) ...клиент испытывает сексуальное влечение к вам?

9) ...клиент сильно отличается от вас по одному или нескольким значимым для вас параметрам (например, раса, вероисповедание, пол, возраст, социальный статус и др.)?

10) ...ценности и убеждения клиента в корне противоречат вашим (например, религиозные убеждения или убеждения относительно гендерных ролей в обществе)?

\section{Часть 3.2. Переживание дистресса клиентом}

Насколько вы уверены, что сможете эффективно работать в течение следующей недели с клиентом, если...

1) ...в недавнем прошлом клиент пережил травматическое событие (например, физическое или психологическое насилие)?

2) ...клиент подвергался сексуальному насилию?

3) ...у клиента клиническая депрессия?

4) ...клиент имеет суицидальные наклонности?

5) ...клиент в высшей степени тревожен?

6) ...клиент проявляет признаки серьезно нарушенного мышления?

Таблица 1.1

Данные по шкалам CASES

\begin{tabular}{|l|c|c|c|c|c|}
\hline & $\begin{array}{c}\text { Навыки } \\
\text { выработки } \\
\text { нового } \\
\text { видения }\end{array}$ & $\begin{array}{c}\text { Навыки } \\
\text { исследования }\end{array}$ & $\begin{array}{c}\text { Навыки } \\
\text { действия }\end{array}$ & $\begin{array}{c}\text { Управление } \\
\text { ходом сессии }\end{array}$ & $\begin{array}{c}\text { Конфликт } \\
\text { отношений }\end{array}$ \\
\hline Средние & 40.9 & 37.3 & 26.3 & 69.9 & 98.9 \\
\hline Минимум & 19.0 & 15.0 & 4.0 & 22.0 & 21.0 \\
\hline Максимум & 54.0 & 45.0 & 36.0 & 90.0 & 144.0 \\
\hline $\begin{array}{l}\text { Среднее } \\
\text { квадратичное } \\
\text { отклонение }\end{array}$ & 6.1 & 4.8 & 5.8 & 10.7 & 20.0 \\
\hline Дисперсия & 37.1 & 23.1 & 34.2 & 113.9 & 401.2 \\
\hline Низкий уровень & Меньше 35 & Меньше 32 & Меньше 20 & Меньше 60 & Меньше 79 \\
\hline Средний уровень & $35-47$ & $32-42$ & $20-32$ & $60-80$ & $79-119$ \\
\hline Высокий уровень & Больше 47 & Больше 42 & Больше 32 & Больше 80 & Больше 119 \\
\hline
\end{tabular}

